\title{
TITLE:
}

\section{The neural basis of individual differences in mate poaching}

$\operatorname{AUTHOR}(\mathrm{S})$ :

Ueda, Ryuhei; Ashida, Hiroshi; Yanagisawa, Kuniaki; Abe, Nobuhito

\section{CITATION:}

Ueda, Ryuhei ...[et al]. The neural basis of individual differences in mate poaching. Social Neuroscience 2017, 12(4): 391-399

\section{ISSUE DATE:}

2017-07-04

URL:

http://hdl.handle.net/2433/224996

\section{RIGHT:}

This is an Accepted Manuscript of an article published by Taylor \& Francis in 'Social Neuroscience' on 2017, available online: http://www.tandfonline.com/10.1080/17470919.2016.1182065.; The full-text file will be made open to the public on 04 July 2018 in accordance with publisher's 'Terms and Conditions for Self-Archiving'.; This is not the published version. Please cite only the published version.; この論文は出版社版でありません。引用の際には出版社版をご磼認ご 利用ください。 
Accepted for publication (Social Neuroscience)

http://dx.doi.org/10.1080/17470919.2016.1182065

2

11 Correspondence to:

12 Ryuhei Ueda

13 Graduate School of Letters, Kyoto University

14 Yoshida-honmachi, Sakyo-ku, Kyoto 606-8501, Japan

15 Phone: $+81-75-753-2753$

$16 \quad$ Fax: $+81-75-753-2835$

17 E-mail: ueda.ryuhei.82w@st.kyoto-u.ac.jp 


\section{Abstract}

2 This study tested the hypothesis that individual differences in the activity of the

3 orbitofrontal cortex, a region implicated in value-based decision making, are associated

4 with the preference for a person with a partner, which could lead to mate poaching.

5 During functional magnetic resonance imaging (fMRI), male participants were

6 presented with facial photographs of (a) attractive females with a partner, (b) attractive

7 females without a partner, (c) unattractive females with a partner, and (d) unattractive

8 females without a partner. The participants were asked to rate the degree to which they

9 desired a romantic relationship with each female using an 8-point scale. The participants rated attractive females higher than unattractive females, and this effect was associated

11 with ventral striatum activation. The participants also indicated lower ratings for

12 females with a partner than for females without a partner, and this effect was associated

13 with parietal cortex activation. As predicted, the participants characterized by higher

14 orbitofrontal activity demonstrated a greater willingness to engage in a romantic

15 relationship with females who have a partner compared with females who do not have a

16 partner. These results are the first to provide a possible neural explanation for why

17 certain individuals are willing to engage in mate poaching.

Keywords: fMRI, individual differences, love, orbitofrontal cortex, reward 
1

2 Romantic love is a universal human phenomenon (Jankowiak and Fischer, 1992) in

which an individual seeks an ideal romantic partner. Social psychological studies have indicated that attractive individuals are selected as dating partners more frequently than

5 less attractive individuals (Berscheid and Dion, 1971; Riggio and Woll, 1984), and

6 individuals who date more attractive people have been reported as feeling more satisfied

7 with their dates (Walster et al., 1966). Consistent with these behavioral findings,

8 numerous neuroimaging studies have demonstrated that reward-related brain areas, such

9 as the ventral striatum and orbitofrontal cortex (OFC), are associated with facial attractiveness (Aharon et al., 2001; Ishai, 2007; Kranz and Ishai, 2006; O'Doherty et al., 2003), indicating that attractive faces are rewarding.

In addition to physical attractiveness, several social factors are associated with behavior related to approaching a potential partner. For example, it is precarious to engage in a romantic relationship with a person who has a partner, which is referred to as human mate poaching (Schmitt and Buss, 2001). Typically, people refrain from engaging in a romantic relationship with a person who has a partner. If the target has a partner, then feelings of psychological distance from the target person are inspired. Therefore, from a cognitive neuroscience perspective, the regulation of mate poaching is thought to at least partially engage neural activity in brain regions responsible for social distance evaluations. One recent study has demonstrated that social distance evaluations recruit activity in the parietal region (Yamakawa et al., 2009).

Although mate poaching is a socially unacceptable behavior that should be individually regulated, such behavior is not uncommon (Schmitt and Buss, 2001; Thompson, 1983; Wiederman, 1997), with certain individuals willing to approach a 
1 person who has a partner. Extramarital affairs are also observed in a number of cultures,

2 despite monogamy usually representing the standard mating system for the human species (Fisher, 1987, 1998). Individuals who engage in mate poaching risk a decrease in their social reputation; however, they may also search for additional opportunities to engage in a romantic relationship with an ideal potential mate. Thus, it is not surprising that there are large individual behavioral differences among individuals in whether they will approach a person with a partner.

Although unreliable, adulterous, and erotophilic individuals have been shown to exhibit a tendency to engage in mate poaching (Schmitt and Buss, 2001), little is known about the neural mechanisms underlying individual differences in mate poaching. A potential neural explanation is that heightened activity in reward-related brain regions in response to a person with a partner facilitates mate poaching; therefore, people who are prone to mate poaching might assign increased value to a female with a partner. Among multiple reward-related brain regions, the medial $\mathrm{OFC}$ is a candidate region closely linked to individual differences regarding the preference for a person with a partner. The OFC is known to be a core region for value-based decision making (Gottfried et al., 2003; O’Doherty et al., 2000; for review, Fellows, 2011; Rangel et al., 2008; Rangel and Hare, 2010; Walton et al., 2015). Among the subregions of the OFC, the medial OFC responds to basic primary rewards (e.g., sexual images), whereas the lateral OFC responds to abstract secondary rewards (e.g., money) (Kringelbach and Rolls, 2004; Sescousse et al., 2010). Other studies have argued that the medial OFC engages in reward-guided decision making based on subjective value (e.g., Lebreton et al., 2009; Noonan et al., 2010; Rolls and McCabe, 2007; Ito et al., 2015), whereas the lateral OFC engages in reward-guided learning (Noonan et al., 2010; Rushworth et al., 2011). 
1 Furthermore, in the context of preference judgments for faces, medial OFC activity is

2 more strongly correlated with preference judgments provided by each individual subject

3 rather than by groups of individuals (Kim et al., 2007). These observations allow us to

4 hypothesize that medial OFC activity is sensitive to individual differences in the

5 preference for a person with a partner.

6 In the present study, male participants undergoing functional magnetic resonance

7 imaging (fMRI) were presented with facial photographs of (a) attractive females with a

8 partner, (b) attractive females without a partner, (c) unattractive females with a partner,

9 and (d) unattractive females without a partner. The participants were asked to rate the degree to which they desired a romantic relationship with each female. Before the experiment, the following hypotheses were established: males were predicted to assign higher rating scores to attractive females than to unattractive females (Berscheid and Dion, 1971; Riggio and Woll, 1984; Walster et al., 1966), which would be correlated with the activation of the ventral striatum and/or the OFC; males were predicted to assign a lower rating to females with a partner than to females without a partner, which correlated with the activation of the parietal cortex; and males who were willing to approach a female with a partner were predicted to exhibit increased activity in the OFC in response to females with a partner relative to females without a partner.

\section{Materials and Methods}

Participants

Thirty-nine right-handed male volunteers with no history of neurological or psychiatric disease participated in this study, and all of the subjects were compensated for their participation. To avoid possible confounding factors caused by gender differences, we 
1 only recruited male subjects. The data from three participants were excluded because of

2 excessive head motion during fMRI scanning. Thus, the present results are based on the

3 remaining 36 participants (mean age $=25.0$ years, range $=20-35$ years). Of these 36

4 participants, 12 had a partner, and the remaining 24 did not have a partner. Because the

5 two groups of subjects did not exhibit differences in the pattern of behavioral data

6 acquired during the fMRI task, all of the subjects were analyzed together (see below).

7 After receiving a detailed description of the study, all of the participants provided

8 written informed consent in accordance with the Declaration of Helsinki and guidelines

9 approved by the Ethical Committee of Kyoto University.

$11 \underline{\text { Stimuli }}$

12 We prepared 150 facial photographs of female Japanese fashion models or actresses that were found in online catalogs or magazines. All of the images were downloaded onto a computer and edited using Adobe Photoshop to produce greater uniformity across the photographs. A separate group of 12 male volunteers who did not participate in the fMRI experiment rated the 150 facial photographs using an 8-point scale of attractiveness, happiness intensity, and facial direction. Based on the mean attractiveness rating score, we chose 60 attractive faces $(\mathrm{M}=4.73, \mathrm{SD}=0.44)$ and 60 unattractive faces $(\mathrm{M}=3.42, \mathrm{SD}=0.33)$ for the fMRI experiment. A $t$-test confirmed a significant difference in the mean attractiveness rating scores between the two sets of faces $(t=18.50, p<.001)$. Then, the 60 attractive faces and 60 unattractive faces were each subdivided into two sets of 30 stimuli. No significant differences in attractiveness were observed between the two attractive sets and the two unattractive sets. At the bottom of the first set of 30 attractive faces and the first set of 30 unattractive faces, the 
1 words "with a partner" were displayed, indicating that the female had a partner.

2 Similarly, at the bottom of the second set of 30 attractive faces and the second set of 30

3 unattractive faces, the words "without a partner" were displayed, indicating that the

4 female had no partner. The assignment of facial stimuli to the partner/non-partner

5 conditions was counterbalanced across the subjects. These four sets of stimuli were

6 matched for the intensity of positive expression and facial direction (all $p$ values $>.10$ ).

7

$8 \quad$ Cognitive task

9 All of the participants underwent fMRI scans while they were presented with facial photographs of the (a) Attractive/Partner (AP, attractive females with a romantic partner), (b) Attractive/non-Partner (AnP, attractive females without a romantic partner), (c) Unattractive/Partner (UP, unattractive females with a romantic partner), and (d) Unattractive/non-Partner (UnP, unattractive females without a romantic partner) females. The participants were asked to rate the degree to which they desired a romantic relationship with each female using an 8 -point scale $(1=$ very little to $8=$ very much). The response device had eight buttons corresponding to the index, middle, ring, and little fingers of the right and left hands. The direction of the Likert scale was counterbalanced across the subjects. A total of 120 facial photographs were individually presented in random order, and each condition consisted of 30 trials. Each stimulus was presented for $2 \mathrm{~s}$, and the trials were separated by a variable fixation interval (4-10 s) to maximize the efficiency of the event-related design (Dale, 1999). The schematic were performed with R version 3.1.1 (R Core Team, 2014). 
$1 \quad$ Image acquisition and analysis

2 The participants were scanned in a 3.0-Tesla Siemens Magnetom Verio MRI scanner

3 with a 12-channel head coil. A T2*-weighted echo planar imaging (EPI) sequence

4 sensitive to BOLD contrast was used for functional imaging with the following

5 parameters: repetition time $(\mathrm{TR})=2,500 \mathrm{~ms}$, echo time $(\mathrm{TE})=30 \mathrm{~ms}$, flip angle $=90^{\circ}$,

6 acquisition matrix $=64 \times 64$, field of view $(\mathrm{FOV})=224 \mathrm{~mm}$, and in-plane resolution $=$

$7 \quad 3.5 \times 3.5 \mathrm{~mm}$. Thirty-nine 3.5-mm-thick axial slices were obtained. A high-resolution

8 (spatial resolution $=1 \times 1 \times 1 \mathrm{~mm}$ ) structural image was also acquired using a

9 T1-weighted magnetization-prepared rapid-acquisition gradient echo (MP-RAGE) pulse sequence. Head motion was restricted using firm padding surrounding the head. Visual stimuli were projected onto a screen and viewed through a mirror attached to the head coil, and behavioral responses were recorded with an 8-button fiber optic response box. The first four volumes were discarded to allow for T1 equilibration effects.

Data preprocessing and statistical analyses were performed using SPM8 (Wellcome Department of Imaging Neuroscience, London, UK). For preprocessing, all of the volumes acquired from each subject were corrected for different slice acquisition times. The resulting images were then realigned to correct for small movements between scans. This process generated an aligned set of images and mean image per subject. Each participant's T1-weighted structural MRI was co-registered to the mean of the realigned EPI images and segmented to separate the gray matter, which was normalized to the gray matter in a template image based on the Montreal Neurological Institute (MNI) reference brain. Using the parameters from this normalization process, the EPI images were also normalized to the MNI template (resampled voxel size $=2 \times 2$

$24 \times 2 \mathrm{~mm}$ ) and smoothed with an 8-mm full-width at half-maximum Gaussian kernel. 
The fMRI data were analyzed using an event-related model. For each participant,

2 the activity associated with each experimental condition (i.e., AP, AnP, UP, and UnP)

was modeled using a canonical hemodynamic response function temporally indexed by stimulus onset. Trials with no responses $(0.5 \%$ of all trials $)$ were excluded from the fMRI analyses. One additional trial was excluded because the subject reported

6 familiarity with the facial stimulus during the post-experiment debriefing. A high-pass

7 filter $(1 / 128 \mathrm{~Hz})$ was used to remove low-frequency noise, and an AR (1) model was employed to correct for temporal autocorrelation.

The parameter estimates (betas) for each condition were calculated for all brain voxels, and the relevant contrasts of the parameter estimates were computed. These contrast images were then incorporated into second-level group comparisons using a random effects model. To identify the brain activation area responsible for the two significant main effects observed in the behavioral data (see below), the following contrasts were calculated: $[(\mathrm{AP}+\mathrm{AnP})$ vs. $(\mathrm{UP}+\mathrm{UnP})]$ and $[(\mathrm{AP}+\mathrm{UP})$ vs. $(\mathrm{AnP}+$ UnP)] and vice versa. In addition to the subtraction analyses, we conducted correlation analyses to clarify the brain activity area responsible for the individual differences in ratings in the cognitive task. Thus, we calculated an index of sensitivity to a partner (iP) for each participant. The iP was calculated based on differences in the rating scores between females with a partner and those without a partner (i.e., mean rating scores of the AP and UP conditions minus those of the AnP and UnP conditions). A higher iP indicated that the participant had a greater desire to engage in a romantic relationship with females with a partner than with females without a partner. Note that we calculated the iP by collapsing across the attractive and unattractive conditions because an interaction effect was not observed in the behavioral data (see below). The iP was 
1 entered as a covariate of interest in the analysis of brain activity based on the contrast of

$2 \quad[(\mathrm{AP}+\mathrm{UP})$ vs. $(\mathrm{AnP}+\mathrm{UnP})]$ to identify the brain regions responsible for individual

3 differences in iP. For each whole-brain analysis, significant results were identified at the

4 statistical threshold of $p<.001$ (uncorrected for multiple comparisons), and only

5 clusters with $>10$ voxels were reported. The peak voxels of clusters that exhibited

6 reliable effects are reported in the MNI coordinates.

7

$8 \quad$ Results

$9 \quad$ Behavioral data

Table 1 displays the mean ratings and reaction times. Each participant's mean ratings are shown in Table S1, which indicates that two-thirds of the participants (24 of the 36 participants) rated females with a partner lower than females without a partner. First, we conducted a three-way analysis of variance (ANOVA) of the mean ratings and included the relationship status of the participants (12 subjects had a partner, and the remaining 24 subjects had no partner at the time of the experiment) as a between-subject factor and attractiveness and partner information of the stimuli as within-subject factors. The ANOVA revealed that the stimuli's attractiveness $(F(1,34)=168.08, p<.001)$ and partner information $(F(1,34)=4.29, p<.05)$ presented significant main effects, whereas the participant's status $(F(1,34)=0.12, p=.73)$ was not significant, and all interactions were not significant (all $p$ values $>.10$ ). Because the participant's status and interactions related to the participant's status did not present significant effects, we examined all of the participants together in the analyses of the behavioral and neuroimaging data. A separate two-way repeated measures ANOVA $(\mathrm{n}=36)$ was performed using the stimuli's attractiveness and partner information as factors, and it 
1 yielded significant main effects of both attractiveness $(F(1,35)=171.25, p<.001)$ and

$2 \operatorname{partner}(F(1,35)=6.30, p<.05)$, although the interaction effect was not significant $(F$

$3(1,35)=0.001, p=.98)$. Thus, male participants desired a romantic relationship with

4 attractive females more than a romantic relationship with unattractive females; similarly,

5 males had a greater desirability for a romantic relationship with females without a

6 partner compared with females with a partner. We confirmed that virtually the same

7 results were obtained using the linear mixed model methodology in which the subjects'

8 ratings are regressed against both the attractiveness ratings (i.e., mean ratings of each

9 stimulus obtained in the pilot study) and partner information (see Supplementary 10 Results).

11 Notably, the desire to pursue attractive females does not appear to be the primary desire (the mean AP rating was 4.08, and the mean AnP rating was 4.37 out of 8 ). We speculate that these results were affected by the "response-set-bias", in which people in Asia tend to avoid choosing extreme points in the Likert scale compared to with people in Western societies (Higgins et al., 2002; Lee et al., 2002; Stening and Everett, 1984). Japanese people show a particularly strong response-set-bias in many different scales (Stening and Everett, 1984). We also emphasize that this bias does not invalidate the observed findings regarding the brain activations. If the participants were to experience a low degree of attractiveness of faces, then the subtraction analyses for neuroimaging data would be likely to underestimate the anticipated effects of attractiveness, thereby providing a conservative test of our predictions. data, and it yielded a significant main effect of attractiveness $(F(1,35)=12.47, p<.01)$, whereas the effect of a partner $(F(1,35)=1.48, p=.23)$ and its interactions $(F(1,35)=$ 
$10.40, p=.53$ ) were not significant. Thus, rating attractive females required more time

2 than rating unattractive females, which is highly consistent with the results of several

3 previous studies (e.g., Ishai, 2007; Kranz and Ishai, 2006).

4

5

$6 \quad$ Imaging data

7 The results of the subtraction analyses are summarized in Table 2. First, to reveal brain activation associated with the main effect of attractiveness, we calculated the following contrast: $[(\mathrm{AP}+\mathrm{AnP})$ vs. $(\mathrm{UP}+\mathrm{UnP})]$. This analysis revealed a significant activation of multiple brain regions, including the bilateral ventral striatum, which is highly consistent with our a priori hypothesis (Figure $2 \mathrm{~A})$. The opposite contrast [(UP + UnP) vs. $(\mathrm{AP}+\mathrm{AnP})]$ did not reveal significant activation.

Second, to reveal the brain activation area associated with the main effect of having a partner, we calculated the following contrast: [(AP + UP) vs. $(\mathrm{AnP}+\mathrm{UnP})]$. This analysis revealed significant activation of the left middle temporal gyrus and left angular gyrus, which is also highly consistent with our hypothesis (Figure 2B). The opposite contrast $[(\mathrm{AnP}+\mathrm{UnP})$ vs. $(\mathrm{AP}+\mathrm{UP})]$ did not reveal significant activation.

Although we did not observe significant interactions in the behavioral data, we identified brain regions that exhibited interaction effects. Specifically, we calculated the following two contrasts: $[(\mathrm{AnP}+\mathrm{UP})$ vs. $(\mathrm{AP}+\mathrm{UnP})]$ and $[(\mathrm{AP}+\mathrm{UnP})$ vs. $(\mathrm{AnP}+$ UP)]. The former contrast indicated significant activation of the right brainstem, but the latter did not. Because brainstem activation was not included in our a priori hypotheses, this finding is not discussed further.

Finally, we conducted a correlation analysis between iP and brain activity based 
1 on the contrast of $[(\mathrm{AP}+\mathrm{UP})$ vs. $(\mathrm{AnP}+\mathrm{UnP})]$ across the participants. At this stage of

2 analysis, one participant was identified as being an outlier (3 SDs below the mean of iP)

3 and was excluded from the analysis $(n=35)$. We observed that the iP was positively

4 correlated with the BOLD signal in the right OFC, which is highly consistent with our

5 hypothesis. Here, we emphasize that even when the outlier was included in the analysis,

6 the results remained virtually unchanged. These results are summarized in Table 3 and

7 illustrated in Figure 3.

9 Discussion

We used fMRI to clarify the brain mechanisms associated with individual differences regarding the preference for a person with a partner. Specifically, we asked male participants to engage in a task that required them to rate their level of desire to engage in a romantic relationship with different females characterized by a combination of two factors: whether the female is attractive and whether the female has a romantic partner. The participants rated attractive females higher than unattractive females, and this effect was associated with activation of the ventral striatum. The participants also rated females with a partner lower than females without a partner, and this effect was associated with activation of the parietal cortex. In addition, higher orbitofrontal activity was associated with a tendency to initiate romantic advances toward females with a partner. To the best of our knowledge, the present study is the first to demonstrate the brain regions involved in individual differences in mate poaching. romantic partner, the remaining participants did not show a decreased preference for females with a romantic partner (see Table S1). Thus, as expected, there are large 
1 individual behavioral differences in whether people will approach a person with a

2 partner. The main finding of the present study is the significant positive correlation

3 between the iP, which is an index of sensitivity to a partner, and medial OFC activity,

4 which is implicated in value-based decision making (Gottfried et al., 2003; O’Doherty

5 et al., 2000; for review, Fellows, 2011; Rangel et al., 2008; Rangel and Hare, 2010;

6 Walton et al., 2015) and response to primary rewards (Kringelbach and Rolls, 2004;

7 Sescousse et al., 2010). This result is highly consistent with our predictions and

8 indicates that people who show heightened OFC activity in response to a female with a

9 partner do not decrease preference for such a female, which could lead to mate poaching in the real world. We propose that the OFC is a critical region that reflects individual differences in mate poaching, with those showing higher OFC activity assigning increased value to a female with a partner but those showing lower OFC activity assigning decreased value to a female with a partner. This idea is consistent with the theory that this region plays a critical role in decisions based on subjective value (Kim et al., 2007; Lebreton et al., 2009; Rolls and McCabe, 2007).

An alternative explanation for the OFC results is that individual differences in mate poaching are associated with risk preference because engaging in infidelity could hurt one's reputation or cause other troubles, including legal problems, vengeance by the target person's partner, or even, in the extreme case, homicide (Wilson and Daly, 1996). Some previous studies have shown that individual differences in medial OFC activity were associated with risky behavior (Van Leijenhorst et al., 2010; Xue et al., 2009), although the exact activation foci in these studies are somewhat different from those in the present study. To directly test the possible relationship between mate poaching and risk-taking, some priming techniques, in which the frequency of 
1 risk-taking behavior is increased in various domains (e.g., Fischer et al., 2007; Mandel, 2 2003), would be informative.

We observed that a lower desire to engage in a relationship with a female who had a partner relative to a female who did not have a partner was also associated with

5 parietal cortex activation, which is highly consistent with our predictions and can be 6 interpreted as a neural correlate of social distance evaluations (Yamakawa et al., 2009).

7 When initiating a romantic advance toward a female, it is important to determine 8 whether the target female already has a romantic partner. If the target female does not 9 have a partner, then males have a greater chance of initiating a relationship with the female. However, if the target female has a partner, then males are unlikely to succeed in love and will typically feel psychologically distanced from the target female. Therefore, to optimize success in romantic relationships, we must evaluate social distance from the target person as a process supported by the parietal cortex. Consistent with previous findings (Aharon et al., 2001; Ishai, 2007; Kranz and Ishai, 2006; O'Doherty et al., 2003), we identified a reward-related brain area associated with the attractiveness of facial stimuli. The higher ratings of attractive females compared with unattractive females were associated with the activation of the ventral striatum, whereas activation of the OFC was not observed. These results suggest a functional dissociation between the ventral striatum and the OFC in the context of amorous decision making; thus, ventral striatum activity may reflect relatively automatic processes for facial attractiveness that are common to participants, whereas OFC activity may be associated with explicit decision-making processes that are sensitive to individual differences. This interpretation is highly consistent with a previous fMRI study in which the ventral striatum was indicated to be more strongly 
1 correlated with preference judgments averaged across the entire group of subjects

2 compared with judgments for individuals; in the same study, OFC activity was more

3 strongly correlated with preference judgments provided by each individual subject than

4 with those averaged across the group (Kim et al., 2007).

In the present study, only male participants were recruited. However, because of

6 the considerable psychological evidence for sex differences in human mate preference,

7 investigating sex differences in the neural correlates for decision making associated

8 with mate poaching is important. For example, males generally desire a romantic

9 relationship with more individuals than females do (Buss and Schmitt, 1993).

10 Furthermore, males tend to emphasize physical attributes, such as physical

11 attractiveness and youthfulness, whereas females tend to emphasize faithfulness, social status, financial status, and ambition (Buss and Schmitt, 1993; Todd et al., 2007; but see also Eastwick and Finkel, 2008). These psychological findings suggest that the neural correlates of decision making associated with mate poaching are dissociable between males and females; however, we will leave this question as a topic for future research.

Another future direction involves examining the mate poaching of people in a non-monogamous (e.g., polygamous) society. To the best of our knowledge, no work has examined how neural networks differ between people in a monogamous society and people in a non-monogamous society. If people in a non-monogamous society feel little hesitancy to initiate multiple romantic relationships even when the opposite sex already has a romantic partner, they might show different neural activation toward a person with a partner compared to people in a monogamous society. This investigation may be helpful in understanding the different social and cultural basis between monogamous and non-monogamous societies. 
1 It is necessary to mention the limitations of the present study. First, our primary

2 results are correlational, which prevented us from making conclusions on the causal

3 relationships between brain activity and decision making with respect to love. Second,

4 the results of the neuroimaging analyses are based on an uncorrected threshold. Further

5 studies are required to determine whether some or all of the results can be replicated.

6 Finally, it is unclear whether the present neural findings can be used to predict actual

7 mate poaching in the real world. Despite these limitations, the present findings do

8 represent an important step toward a neural explanation of socially unacceptable

9 behavior in love in some societies.

\section{Acknowledgments}

12 This study was conducted using the MRI scanner and related facilities of the Kokoro

13 Research Center, Kyoto University. Nobuhito Abe was supported by The Uehiro

14 Foundation on Ethics and Education.

16 Disclosure statement

17 No potential conflict of interest was reported by the authors.

$19 \quad$ Funding

20 This work was partly supported by ImPACT Program of Council for Science,

21 Technology and Innovation (Cabinet Office, Government of Japan). 
1

\section{References}

Aharon, I., Etcoff, N., Ariely, D., Chabris, C. F., O'Connor, E., \& Breiter, H. C. (2001). Beautiful faces have variable reward value: fMRI and behavioral evidence. Neuron, $32,537-551$

Berscheid, E., \& Dion, K. (1971). Physical attractiveness and dating choice: a test of the matching hypothesis. Journal of Experimental Social Psychology, 7, 173-189.

Buss, D. M., \& Schmitt, D. P. (1993). Sexual strategies theory: an evolutionary perspective on human mating. Psychological Review, 100, 204-232.

Dale, A. M. (1999). Optimal experimental design for event-related fMRI. Human Brain Mapping, 8, 109-114.

Eastwick, P. W., \& Finkel, E. J. (2008). Sex differences in mate preferences revisited: Do people know what they initially desire in a romantic partner? Journal of Personality and Social Psychology, 94, 245-264.

Fellows, L. K. (2011). Orbitofrontal contributions to value-based decision making: evidence from humans with frontal lobe damage. Annals of the New York Academy of Sciences, 1239, 51-58.

Fischer, P., Kubitzki, J., Guter, S., \& Frey, D. (2007). Virtual driving and risk taking: do racing games increase risk-taking cognitions, affect, and behaviors? Journal of Experimental Psychology: Applied, 13, 22-31.

Fisher, H. (1987). The four-year itch. Natural History, 96, 22-33.

Fisher, H. (1998). Lust, attraction, and attachment in mammalian reproduction. Human

$$
\text { Nature, 9, 23-52. }
$$

Gottfried, J. A., O’Doherty, J., \& Dolan, R. J. (2003). Encoding predictive reward value in human amygdala and orbitofrontal cortex. Science, 301, 1104-1107. 
1 Higgins, L. T., Zheng, M., Liu, Y., \& Sun, C. H. (2002). Attitudes to marriage and sexual behaviors: A survey of gender and culture differences in China and United Kingdom. Sex Roles, 46, 75-89.

Ishai, A. (2007). Sex, beauty and the orbitofrontal cortex. International Journal of Psychophysiology, 63, 181-185.

6 Ito, A., Abe, N., Kawachi, Y., Kawasaki, I., Ueno, A., Yoshida, K., Sakai, S., Matsue,

$7 \quad$ Y., \& Fujii, T. (2015). Distinct neural correlates of the preference-related valuation of supraliminally and subliminally presented faces. Human Brain Mapping, 36, 2865-2877.

Jankowiak, W. R., \& Fischer, E. F. (1992). A cross-cultural perspective on romantic love. Ethnology, 31, 149-155.

Kim, H., Adolphs, R., O'Doherty, J. P., \& Shimojo, S. (2007). Temporal isolation of Neurobiology, 72, 341-372. neural processes underlying face preference decisions. Proceedings of the National Academy of Sciences, 104, 18253-18258.

Kranz, F., \& Ishai, A. (2006). Face perception is modulated by sexual preference. Current Biology, 16, 63-68.

Kringelbach, M. L., \& Rolls, E. T. (2004). The functional neuroanatomy of the human orbitofrontal cortex: evidence from neuroimaging and neuropsychology. Progress in

Lebreton, M., Jorge, S., Michel, V., Thirion, B., \& Pessiglione, M. (2009). An automatic valuation system in the human brain: evidence from functional neuroimaging. Neuron, 64, 431-439.

Lee, J. W., Jones, P. S., Mineyama, Y., \& Zhang, X. E. (2002). Cultural differences in response to a Likert scale. Research in Nursing and Health, 25, 295-306. 
1 Mandel, N. (2003). Shifting selves and decision making: the effects of self-construal 2 priming on consumer risk-taking. Journal of Consumer Research, 30, 30-40.

3 Noonan, M. P., Walton, M. E., Behrens, T. E. J., Sallet, J., Buckley, M. J., \& Rushworth, M. F. S. (2010). Separate value comparison and learning mechanisms in macaque medial and lateral orbitofrontal cortex. Proceedings of the National Academy of

$6 \quad$ Sciences, 107, 20547-20552.

7 O’Doherty, J., Rolls, E. T., Francis, S., Bowtell, R., McGlone, F., Kobal, G., Renner, B., \& Ahne, G. (2000). Sensory-specific satiety-related olfactory activation of the human orbitofrontal cortex. NeuroReport, 11, 893-897.

O'Doherty, J., Winston, J., Critchley, H., Perrett, D., Burt, D. M., \& Dolan, R. J. (2003). Beauty in a smile: the role of medial orbitofrontal cortex in facial attractiveness. Neuropsychologia, 41, 147-155.

R Core Team. (2014). R: A Language and Environment for Statistical Computing. R Foundation for Statistical Computing: Vienna, Austria. <http://www.R-projecr.org/> (URL).

Rangel, A., Camerer, C., \& Montague, P. R. (2008). A framework for studying the neurobiology of value-based decision making. Nature Reviews Neuroscience, 9, $545-556$.

Rangel, A., \& Hare, T. (2010). Neural computations associated with goal-directed choice. Current Opinion in Neurobiology, 20, 262-270.

Riggio, R. E., \& Woll, S. B. (1984). The role of nonverbal cues and physical attractiveness in the selection of dating partners. Journal of Social and Personal Relationships, 1, 347-357.

24 Rolls, E. T., \& McCabe, C. (2007). Enhanced affective brain representations of 
1 chocolate in cravers vs. non-cravers. European Journal of Neuroscience, 26, $2 \quad 1067-1076$.

3 Rushworth, M. F. S., Noonan, M. P., Boorman, E. D., Walton, M. E., \& Behrens, T. E. (2011). Frontal cortex and reward-guided learning and decision-making. Neuron, 70, 1054-1069.

6 Schmitt, D. P., \& Buss, D. M. (2001). Human mate poaching: Tactics and temptations

7 for infiltrating existing mateships. Journal of Personality and Social Psychology, 80, 894-917.

9 Sescousse, G., Redouté, J., \& Dreher, J. C. (2010). The architecture of reward value coding in the human orbitofrontal cortex. Journal of Neuroscience, 30, 13095-13104.

Stening, B. W., \& Everett, J. E. (1984). Response styles in a cross-cultural managerial study. Journal of Social Psychology, 122, 151-156.

Thompson, A. P. (1983). Extramarital sex: A review of the research literature. Journal of Sex Research, 19, 1-22.

Todd, P. M., Penke, L., Fasolo, B., \& Lenton, A. P. (2007). Different cognitive processes underlie human mate choices and mate preferences. Proceedings of the National Academy of Sciences, 104, 15011-15016.

Van Leijenhorst, L., Moor, B. G., de Macks, Z. A. O., Rombouts, S. A. R. B., Westenberg, P. M., \& Crone, E. A. (2010). Adolescent risky decision-making: Neurocognitive development of reward and control regions. Neuroimage, 51, $345-355$.

Walster, E., Aronson, V., Abrahams, D., \& Rottman, L. (1966). Importance of physical attractiveness in dating behavior. Journal of Personality and Social Psychology, 4, 508-516. 
1 Walton, M. E., Chau, B. K. H., \& Kennerley, S. W. (2015). Prioritising the relevant

2 information for learning and decision making within orbital and ventromedial

3 prefrontal cortex. Current Opinion in Behavioral Sciences, 1, 78-85.

4 Wiederman, M. W. (1997). Extramarital sex: Prevalence and correlates in a national $5 \quad$ survey. Journal of Sex Research, 34, 167-174.

6 Wilson, M. I., \& Daly, M. (1996). Male sexual proprietariness and violence against 7 wives. Current Directions in Psychological Science, 5, 2-7.

8 Xue, G., Lu, Z., Levin, I. P., Weller, J. A., Li, X., \& Bechara, A. (2009). Functional 9 dissociations of risk and reward processing in the medial prefrontal cortex. Cerebral $10 \quad$ Cortex, 19, 1019-1027.

11 Yamakawa, Y., Kanai, R., Matsumura, M., \& Naito, E. (2009). Social distance evaluation in human parietal cortex. PLoS One, 4, e4360. 
1 Tables

2

Table 1. Ratings and reaction times

\begin{tabular}{lcccc}
\hline & Mean & SD & Mean & SD \\
\hline AP & 4.08 & 1.17 & 1,830 & 593 \\
AnP & 4.37 & 0.90 & 1,836 & 640 \\
UP & 2.86 & 0.88 & 1,746 & 572 \\
UnP & 3.15 & 0.86 & 1,775 & 602 \\
& & & & \\
AP, Attractive/Partner; AnP, Attractive/non-Partner; UP, Unattractive/Partner; UnP, \\
Unattractive/non-Partner
\end{tabular}


Table 2. Regions showing activation in subtraction analyses

\begin{tabular}{|c|c|c|c|c|c|}
\hline \multirow[t]{2}{*}{ Region (Brodmann's Area) } & \multicolumn{3}{|c|}{$\begin{array}{c}\text { MNI } \\
\text { coordinates }\end{array}$} & \multirow{2}{*}{$\begin{array}{c}\mathrm{Z} \\
\text { value }\end{array}$} & \multirow{2}{*}{$\begin{array}{l}\text { Cluster } \\
\text { size }\end{array}$} \\
\hline & $x$ & $Y$ & $z$ & & \\
\hline
\end{tabular}

Effect of attractive faces: $(\mathrm{AP}+\mathrm{AnP})$ vs. $(\mathrm{UP}+\mathrm{UnP})$

Left superior frontal gyrus (9)

$\begin{array}{lllll}-26 & 40 & 40 & 4.46 & 136\end{array}$

Left superior frontal gyrus (medial) (32)

$\begin{array}{lllll}-8 & 28 & 38 & 3.90 & 67\end{array}$

Left insula

$\begin{array}{lllll}-26 & 22 & -2 & 5.29 & 318\end{array}$

Left precentral gyrus (44)

$-44 \quad 4 \quad 30$

3.86

307

Left pallidum/ventral striatum

$\begin{array}{lll}-12 & 4 & -6\end{array}$

4.30

246

Left posterior cingulate cortex (23)

$\begin{array}{lll}-8 & -34 & 28\end{array}$

3.81

95

Left inferior temporal gyrus (20)

$\begin{array}{lll}-52 & -48 & -10\end{array}$

3.59

20

Left inferior temporal gyrus (37)

$-48 \quad-66 \quad-4$

3.55

50

Left cuneus (18)

$\begin{array}{lll}-12 & -90 & 14\end{array}$

3.30

18

Left/right cerebellum

$\begin{array}{lll}0 & -62 & -24\end{array}$

3.27

18

Right anterior cingulate cortex (32)

$\begin{array}{lll}14 & 22 & 38\end{array}$

4.03

155

Right insula

$\begin{array}{lll}34 & 16 & -6\end{array}$

4.42

478

Right pallidum/ventral striatum

$\begin{array}{lll}10 & 2 & -6\end{array}$

4.48

360

Right superior frontal gyrus (medial) (6)

$\begin{array}{lll}28 & 2 & 44\end{array}$

3.80

81

Right insula

$\begin{array}{lll}40 & -12 & 26\end{array}$

3.39

27

Right hippocampus

$\begin{array}{lll}24 & -30 & -4\end{array}$

3.33

18

Right posterior cingulate gyrus (23)

$\begin{array}{lll}8 & -38 & 26\end{array}$

3.51

32

Right calcarine cortex (18)

$\begin{array}{lll}24 & -64 & 14\end{array}$

4.68

5,836

Right cerebellum

$36-66-50$

4.32

171

Right cerebellum

$\begin{array}{lll}6 & -72 & -26\end{array}$

3.38

35

Right fusiform gyrus (19)

$\begin{array}{llll}30 & -76 & -2 & 3.43\end{array}$

\section{Effect of unattractive faces: $(\mathrm{UP}+\mathrm{UnP})$ vs. $(\mathrm{AP}+\mathrm{AnP})$}

No suprathreshold voxels

\section{Effect of partner: $(A P+$ UP) vs. $(A n P+U n P)$}

Left middle temporal gyrus (21)

$\begin{array}{cccc}-58 & -40 & 0 & 4.00 \\ -50 & -56 & 28 & 3.94\end{array}$

Left angular gyrus (39) 
Effect of non-partner: $(A n P+U n P)$ vs. $(A P+U P)$

No suprathreshold voxels

Interaction: (AnP + UP) vs. (AP + UnP)

Right brainstem

$\begin{array}{llll}4 & -28 & -12 & 3.60\end{array}$

19

Interaction: $(\mathrm{AP}+\mathrm{UnP})$ vs. $(\mathrm{AnP}+\mathrm{UP})$

No suprathreshold voxels

AP, Attractive/Partner; AnP, Attractive/non-Partner; UP, Unattractive/Partner; UnP, Unattractive/non-Partner

$p<.001$ uncorrected, $\mathrm{k}>10$ voxels 
1

Table 3. Regions showing significant correlations between the iP and activity

difference $[(A P+U P)$ vs. $(A n P+U n P)]$

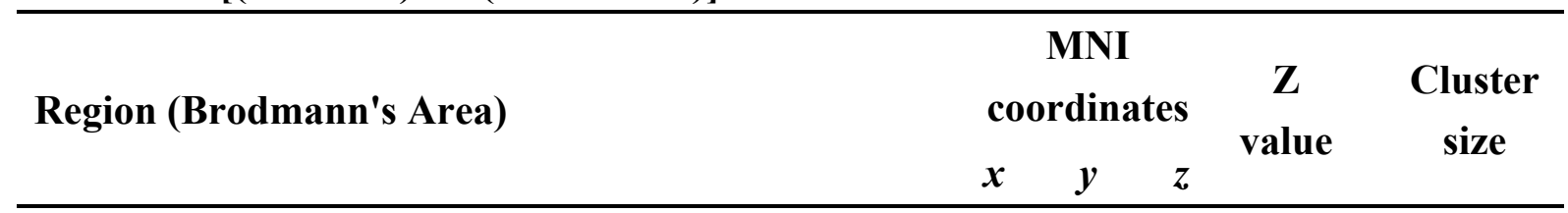

\section{Positive correlation}

Right orbitofrontal cortex (11)

$\begin{array}{lllll}14 & 56 & -6 & 4.01 & 26\end{array}$

Right rolandic operculum (6)

$\begin{array}{lllll}62 & 8 & 8 & 3.45 & 18\end{array}$

Right superior parietal lobule (2)

$\begin{array}{lllll}44 & -44 & 62 & 4.26 & 61\end{array}$

Right precuneus (subcortical white matter)

$\begin{array}{llll}28 & -50 & 26 & 3.45\end{array}$

\section{Negative correlation}

No suprathreshold voxels

$\mathrm{iP}$, an index of sensitivity to partner; AP, Attractive/Partner; AnP, Attractive/non-Partner; UP, Unattractive/Partner; UnP, Unattractive/non-Partner $p<.001$ uncorrected, $\mathrm{k}>10$ voxels 


\section{$1 \quad$ Figure Legends}

2 Figure 1

3 Schematic diagram of the experimental design. The participants rated the degree to

4 which they desired a romantic relationship with each female presented on the screen

5 using an 8 -point scale $(1=$ very little to $8=$ very much). The study included the

6 following four experimental conditions: (a) Attractive/Partner (AP, attractive females

7 with a romantic partner), (b) Attractive/non-Partner (AnP, attractive females without a

8 romantic partner), (c) Unattractive/Partner (UP, unattractive females with a romantic

9 partner), and (d) Unattractive/non-Partner (UnP, unattractive females without a 10 romantic partner).

13 Figure 2

14 (A) Activation of the ventral striatum bilaterally based on the contrast of [(AP + AnP $)$ vs. (UP $+\mathrm{UnP})]$, indicating that these regions were sensitive to attractive faces. (B) Activation of the left angular gyrus based on the contrast of $[(\mathrm{AP}+\mathrm{UP})$ vs. (AnP + UnP)], indicating that this region was sensitive to partner information. AP, Attractive/Partner; AnP, Attractive/non-Partner; UP, Unattractive/Partner; UnP, 19 Unattractive/non-Partner.

Figure 3

23 The right $\mathrm{OFC}$ revealed a significant positive correlation between the iP (mean rating scores of the AP and UP conditions minus those of the AnP and UnP conditions) and 
1 activity difference $[(\mathrm{AP}+\mathrm{UP})$ vs. $(\mathrm{AnP}+\mathrm{UnP})]$, indicating that individuals who

2 exhibited higher activity in this region were more willing to be in a romantic

3 relationship with females who have a partner. In the scatter plot, the $x$-axis shows the

4 percentage change in the BOLD signal in the right OFC for each subject, and the $y$-axis

5 shows each subject's iP. OFC, orbitofrontal cortex; iP, index of sensitivity to partner 6 status. 


\section{Supplementary Results}

$2 \quad$ Multiple regression analysis for ratings

3 For the rating scores of the behavioral data, we used a linear mixed effects model 4 (Baayen et al., 2008) to confirm the relative impact of the presence of a partner 5 controlling for attractiveness of stimuli. The participants' ratings were analyzed with

6 linear mixed effects models using the packages lme4 (Bates et al., 2014) and lmerTest 7 (Kuznetsova et al., 2015), available for R statistical software (R Core Team, 2014). We

8 included each stimulus's attractiveness (i.e., the mean-centered average attractiveness 9 ratings of each female face stimuli measured in the pilot study) and partner information (i.e., with a partner: -1 , without a partner: 1) and their interaction effect as fixed effects. We also included random intercepts for stimuli and participants as well as random participant slopes for the main effects and their interaction (Barr et al., 2013). The regression analysis demonstrated significant main effects of attractiveness $(B=0.92, p$ $<.001)$ and partner information $(B=0.15, p<.05)$, but there was no significant interaction effect $(B=0.03, p=.25)$, confirming the significant impact of partner information irrespective of the attractiveness of the stimuli.

\section{Supplementary References}

Baayen, R. H., Davidson, D. J., \& Bates, D. M. (2008). Mixed-effects modeling with crossed random effects for subjects and items. Journal of Memory and Language, 59, $390-412$.

Barr, D. J., Levy, R., Scheepers, C., \& Tily, H. J. (2013). Random effects structure for confirmatory hypothesis testing: Keep it maximal. Journal of memory and language, $68,255-278$. 
1 Bates, D., Maechler, M., Bolker, B., \& Walker, S. (2014). lme4: Linear mixed-effects

2 models using Eigen and S4. R package version 1. 1-7.

3 Kuznetsova, A., Brockhoff, P. B., \& Christensen, R. H. B. (2015). lmerTest: Tests in

4 linear mixed effects models (Version 2.0-25) [Software]. Retrieved from

$5 \quad$ http://cran.r-project.org/web/packages/lmerTest/.

6 R Core Team. (2014). R: A Language and Environment for Statistical Computing. R: A

7 language and environment for statistical computing. Vienna: R Foundation for

8 Statistical Computing. Retrieved from http://www.R-projecr.org/ 
$2 \quad$ Table S1. All of the participants' mean ratings data

\begin{tabular}{|c|c|c|c|c|c|}
\hline & AP & $\mathrm{AnP}$ & UP & UnP & iP \\
\hline Participant 1 & 5.83 & 4.83 & 3.83 & 3.77 & 0.53 \\
\hline Participant 2 & 4.62 & 3.88 & 2.63 & 2.41 & 0.48 \\
\hline Participant 3 & 5.17 & 4.90 & 5.52 & 4.83 & 0.48 \\
\hline Participant 4 & 3.30 & 3.07 & 2.73 & 2.40 & 0.28 \\
\hline Participant 5 & 5.00 & 5.10 & 3.80 & 3.30 & 0.20 \\
\hline Participant 6 & 4.07 & 4.03 & 2.70 & 2.40 & 0.17 \\
\hline Participant 7 & 4.63 & 4.13 & 2.60 & 2.80 & 0.15 \\
\hline Participant 8 & 5.33 & 5.40 & 3.87 & 3.50 & 0.15 \\
\hline Participant 9 & 4.53 & 4.47 & 2.73 & 2.53 & 0.13 \\
\hline Participant 10 & 4.97 & 4.77 & 3.23 & 3.20 & 0.12 \\
\hline Participant 11 & 5.63 & 5.37 & 4.20 & 4.30 & 0.08 \\
\hline Participant 12 & 3.43 & 3.70 & 1.83 & 1.50 & 0.03 \\
\hline Participant 13 & 3.93 & 4.33 & 2.73 & 2.43 & -0.05 \\
\hline Participant 14 & 3.97 & 3.87 & 2.77 & 3.03 & -0.08 \\
\hline Participant 15 & 4.77 & 4.83 & 2.90 & 3.03 & -0.10 \\
\hline Participant 16 & 5.10 & 4.73 & 3.50 & 4.07 & -0.10 \\
\hline Participant 17 & 2.17 & 2.40 & 1.67 & 1.70 & -0.13 \\
\hline Participant 18 & 1.37 & 1.53 & 1.00 & 1.10 & -0.13 \\
\hline Participant 19 & 3.83 & 4.10 & 2.73 & 2.77 & -0.15 \\
\hline Participant 20 & 5.97 & 5.80 & 3.67 & 4.13 & -0.15 \\
\hline Participant 21 & 5.00 & 5.30 & 2.93 & 2.97 & -0.17 \\
\hline Participant 22 & 3.87 & 4.23 & 2.90 & 2.87 & -0.17 \\
\hline Participant 23 & 4.37 & 4.73 & 2.97 & 3.03 & -0.22 \\
\hline Participant 24 & 5.13 & 4.67 & 2.97 & 3.97 & -0.27 \\
\hline Participant 25 & 4.20 & 4.53 & 3.37 & 3.57 & -0.27 \\
\hline Participant 26 & 4.31 & 4.55 & 3.63 & 3.93 & -0.27 \\
\hline Participant 27 & 2.30 & 2.57 & 1.37 & 1.67 & -0.28 \\
\hline Participant 28 & 4.27 & 4.67 & 3.21 & 3.40 & -0.30 \\
\hline Participant 29 & 4.37 & 5.00 & 3.13 & 3.60 & -0.55 \\
\hline Participant 30 & 4.27 & 5.07 & 3.07 & 4.03 & -0.88 \\
\hline Participant 31 & 3.97 & 5.13 & 2.67 & 3.37 & -0.93 \\
\hline Participant 32 & 3.40 & 4.53 & 2.27 & 3.07 & -0.97 \\
\hline Participant 33 & 3.83 & 5.10 & 2.57 & 3.70 & -1.20 \\
\hline Participant 34 & 1.97 & 3.33 & 1.87 & 3.10 & -1.30 \\
\hline Participant 35 & 2.27 & 3.97 & 2.10 & 3.37 & -1.48 \\
\hline Participant 36 & 1.60 & 4.77 & 1.23 & 4.63 & $-3.28^{*}$ \\
\hline
\end{tabular}

AP, Attractive/Partner; AnP, Attractive/non-Partner;

UP, Unattractive/Partner; UnP, Unattractive/non-Partner

iP, an index of sensitivity to partner; * indicates an outlier (3 SD below the mean of the iP), which was excluded from the correlation analysis. 